\title{
RECUPERACIÓN DE LOS RESTOS DE LA SILLERÍA DE LA CATEDRAL DE HUESCA
}

\author{
POR \\ ANTONIO NAVAL MÁS \\ Universidad de Castilla-La Mancha
}

\begin{abstract}
La sillería del coro de la catedral de Huesca estuvo en el centro de la nave hasta diciembre de 1969 en que se desmontó. De sus 85 sillas, 28 fueron colocadas en el presbiterio y el resto ha sido definitivamente montado y expuesto en el Museo Diocesano. Es fundamentalmente de las incidencias de este proceso de lo que se deja constancia. Se adjuntan, a su vez, las notas que aclaran los trabajos de recuperación, limpieza y montaje, así como aquellas alteraciones que fueron inevitables en el orden de las piezas que quedaron volantes, y las sustituciones y reintegraciones. Todo ello habrá que tenerse en cuenta en cuantos estudios se quieran hacer en el futuro sobre esta destacada sillería.
\end{abstract}

Palabras clave: Sillería de coro. Catedral Huesca. Escultura s. Xvi.

The choir stalls of Huesca Cathedral were situated in the center of the nave until December, 1969, when they were removed. Of the 85 seats, 28 were placed in the chancel and the remainder mounted and exhibited in the Diocesan Museum. This study deals mainly with this process, and includes information concerning the restoration, cleaning and mounting of these pieces, as well as the inevitable changes in their order. Future studies of this outstanding work will have to take into account all of these alterations.

Key words: Choir Stalls. Huesca Cathedral. Sculpture XVI century.

La sillería del coro de la Catedral de Huesca, siguiendo la tradición española, estuvo en el centro de la iglesia, ocupando en la nave central los dos primeros tramos a partir del transepto. A finales de 1969 se comenzó su desmontaje con ocasión de la restauración que entonces se iniciaba en el interior de la catedral. Tres años después, una parte de la misma era colocada en los laterales del retablo mayor. El resto quedaría en el claustro gótico donde permaneció amontonada aproximadamente durante nueve años. Después, fue acomodada en la antigua sala capitular, por lo cual fue desmontada la cadiera, o banco corrido, probablemente del xvIII, que rodeaba esta sala. En 1997 la sillería fue nuevamente desmontada con motivo de la rehabilitación de esta sala como Sala de Orfebrería del Museo Diocesano. Finalmente, en 1999, se comenzó la instalación definitiva en la iglesia de la parroquia de la Catedral para formar parte del Museo Diocesano, en el que es una pieza destacada. Para poder montarla en este lugar fue necesario prolongar el piso del coro alto de esta iglesia. Allí se han colocado los tramos de sédalos que estaban montados en la sala capitular y los que, fragmentados, estaban en la antesala, al haber sido imposible colocar todas las sillas sobrantes por ser espacio insuficiente el espacio de la sala capitular.

El criterio de exposición en su nuevo emplazamiento ha sido de concepción museística. Es decir, se han acomodado los tramos de sillería que no fueron colocados en el presbiterio, al 
espacio disponible, con la precaución prioritaria de no trocearlos más. El nuevo espacio estaba condicionado por el acceso actual, que, a su vez, ha condicionado la disposición del conjunto. Con ellos se ha querido evocar el entorno de un coro, pero se ha evitado reinventar un nuevo coro subordinado a las disponibilidades de espacio. Eso explica que no haya una silla principal y central, y que solo uno de los rincones sea achaflanado, lo cual no hubiera sido así en el caso de que se hubiera tallado una sillería para este nuevo lugar. La silla principal está en la catedral así como una de las sillas esquineras o rincón, de canónigos, y los dos atriles que había detrás de cada una de las sillas esquineras de beneficiados. Al ser más reducido el nuevo espacio disponible la apariencia del coro en su conjunto es más angosto, porque el ancho de este nuevo espacio es menor que el de la nave central de la catedral. Se han recuperado, no obstante, los desniveles entre sillas altas y bajas, que venían marcados por las huellas de los escalones en las piezas conservadas. Así mismo, se ha recuperado la parte correspondiente a una de las dos puertas de acceso, desaparecidas. Aquella ha sido sustituida por una nueva que recompone la geometrización que la adornaba, pero que aparece desprovista de toda imitación de ornamentación en bajorrelieve.

Es conocida la característica de las catedrales españolas donde, de forma un tanto desconcertante para nuestros criterios, se instalaron en el centro de la nave central las sillerías, interrumpiendo la perspectiva de la iglesia, ocultando la mayor parte de las veces buenos retablos mayores y limitando la función del templo si no llegaba a inutilizarlo. Era consecuencia, de la relevancia que adquirieron los cabildos, formados por numerosos canónigos y beneficiados. A ellos había que añadir los capellanes y otros clérigos al servicio de las catedrales. En Huesca, en el siglo xvI, llegaron a ser más de ochenta los sacerdotes vinculados a la catedral ${ }^{1}$.

El decreto sobre Sagrada Liturgia promulgado con ocasión del Concilio Vaticano II, que inculcaba la participación de los fieles en las celebraciones litúrgicas, fue el motivo de la eliminación de coros como el de la Catedral de Huesca. Lo cierto es que este decreto, si bien estimulaba esta participación, también llamaba la atención sobre el papel que las obras de arte han desempeñado en la vida de la iglesia y alentaba a su conservación. A pesar de ello, el decreto fue en muchos casos interpretado parcialmente, y en un desmesurado celo por perseguir esa participación se atropellaron gran parte de obras de arte que pasaron a almacenes si no fueron mal vendidas.

Pocos años después de que finalizara el Concilio (1965), la catedral de Huesca tuvo la suerte de contar con ayuda pública para su restauración, pero al mismo tiempo, fue víctima de esta equivocada interpretación del Decreto del Concilio. En 1969, con gran regocijo, por haber obtenido el beneplácito del cabildo catedralicio, los responsables de la restauración procedieron al desmontaje de la sillería. En ese momento no se sopesó bien antes del desmantelamien-

1 A. Durán Gudiol, Historia de la Catedral de Huesca, Huesca, IEA 1991, p. 147; Aynsa Francisco, Diego, Fundación, excelencias, grandezas y cosas memorables de la antiquísima ciudad e Huesca, Huesca 1619, p. 510; P. Ramón de Huesca, Teatro Histórico y Monumental de las Iglesias d Aragón, Pamplona 1972, T. VII, p. 6; Arco Garay, R. del, Guía artística y monumental de Huesca y su provincia, Huesca 1910, p. 37; Arco Garay, R. del, Estudios varios, pp. 11-14, Huesca 1911: aparece publicado el protocolo de 1587; Arco Garay, R. del, «La custodia y la sillería del coro de la Catedral de Huesca» en Linajes de Aragón, t. II, núm. 11 (1 de junio de 1911), pp. 202, y t. II, núm. 12 (15 junio 1911), pp. 224-227 Aparece publicado el protocolo de 1587; Arco Garay, R. del, «Nuevo Paseo arqueológico por la Ciudad de Huesca, con datos artísticos y documentales inéditos», en Arte Español, t. IV (1918-19), p. 90; Arco Garay, R., «El Arte en la Catedral de Huesca, noticias arqueológicas y documentales inéditas», en Vell y nou, vol. I, num. X, época II, enero 1921 , pp. 387392; Arco Garay, R. del, La catedral de Huesca, monografía histórico arqueológica, Huesca 1924, p. 114-118; Arco Garay, R. del, Catalogo Monumental, Huesca, Madrid 1942, p. 104 ; Arco Garay, R. del: «Nuevas Noticias de Artistas Altoaragoneses» en Archivo Español del Arte, XX ( 1947) pp. 216-239.; Arco Garay, R. del, «El Coro de la Catedral de Huesca» en Universidad, Revista de Cultura y Vida Universitaria Zaragoza, (octubre-diciembre 1949) p. 581 590. Aparece publicado el protocolo de 1587; Arco Garay, R. del, «La Sillería del Coro de la Catedral de Huesca», Zaragoza, Cuadernos de Arte Aragonés núm. 5, 1953, 10 pp. Ilust. Precisa algunos temas de la iconología tras la aportación de Tormo Cervino; Arco Garay, R.: «La Catedral de Huesca. El coro, datos documentales, en Fiestas de San Lorenzo (Programa, 1965).

$A E A$, LXXVI, 2003, 302, pp. 153 a 167 
to si los restos que no iban a ser colocados en el presbiterio cabían en algún lugar de los disponibles. Tampoco se levantó documentación ni de planos ni siquiera fotográfica, que dejara constancia de las características de lo que iba a desmontarse, y no se hizo ningún inventario de lo que quedaba errante. Y lo que es más incomprensible, no se percibió el alcance de la decisión olvidando que la Sillería de Coro de la Catedral de Huesca era un excelente trabajo de madera de roble.

\section{Información documental}

Habían dado noticias relacionadas con este trabajo de carpintería tanto Diego de Aynsa como el Padre Ramón de Huesca. Los datos documentales relacionados con este trabajo de carpintería fueron publicados en varias ocasiones por D. Ricardo del Arco Garay con textos prácticamente invariables desde que publicó la capitulación en $1911^{2}$.

La colocación de la sillería se terminó en 1591, según una nota escrita que dejó oculta el mismo Juan Berroeta en la parte alta del templete que corona la silla episcopal. La nota fue encontrada al comenzar el desmontaje de la sillería, en enero de 1970. Por este papel sabemos que también trabajó Juan de Liébana, hasta este momento desconocido, que fue contratado por dos años, en realidad el tiempo aproximado que medió entre la muerte de Nicolás y la finalización del trabajo. La nota que fue publicada por D. Antonio Durán Gudiol dice lo siguiente:

«año 1591 se acabó de rematar las obras de la sillas del coro. Fue dicha obra principiada por Nicolás de Berroeta, natural de la provincia de Guipuscoa, murió el año 1589 y quando principada la dicha obra la qual acabe yo Juan de Berroeta, su hijo en compañía de Joan de Allí, el qual asistió a la dicha obra en todo tiempo des principio asta el fin; también asistió Joanes de Luebana en mi compañía por tiempo de dos años, el qual se alló asta el fin de la obra...y se acabó en el día 1591 por el mes de abril y a 10 y fue escrito sobre el propio remate do se alla (este papel) estando con la rudilla sobre la pared Juan de Berroeta ${ }^{3}$.

Según este autor en la misma publicación, los primeros encuentros entre los canónigos y el maestro fueron iniciados el 19 de noviembre de 1577, adelantando, por lo tanto, en diez años los contactos entre el cabildo y el maestro, y, consecuentemente, el tiempo que duró la construcción de la sillería. Añade, además, que en un primer momento obraba la sillería en su lugar de origen, mandando después a Huesca la madera o los distintos adornos, sin embargo, en fecha indeterminada trasladó su taller a Huesca. Por lo tanto, relacionando esta aportación con la noticia dada por Arco Garay lo que en 1586 se hizo fue nombrar una comisión «para que se vea con maestre Nicolás, maestro de coro y vean las sillas que están hechas, cómo se han de poner y de ancho y largo, etc. y hagan una capitulación con él y la traigan ${ }^{4}$. Con la visita los canónigos comisionados llegaron a un acuerdo definitivo por lo que la capitulación se firmó el 9 de enero de 1587.

En realidad tal como se afirma en la capitulación estaban hechas las sillas centrales o de cabecera:...«cada una de las tres sillas que mre Nicholas hiço y estan en el choro assentadas,

\footnotetext{
${ }^{2}$ Por estas noticias sabemos que el contrato fue hecho en 1587 por el maestro carpintero Nicolás de Beraztegui, y que este murió pronto, siendo su yerno-hijo, conocido como Juan de Berroeta, y un ayudante llamado Juan de Allí, los que llevaron a término el trabajo.

${ }^{3}$ Durán Gudiol, A., Historia de la Catedral de Huesca, Huesca, 1991, pp. 181-185.

${ }^{4}$ Existía una sillería que había sido hecha en 1401 por un moro de Borja, que ahora querían sustituir por un nuevo trabajo. El maestro Nicolás recibió la sillería antigua como parte del pago de la nueva obra.
} 
es a saber, la silla episcopal y las otras dos de los assistentes»....También lo estaba, «el facistol labrado que esta hecho para dicha silla episcopal» ${ }^{5}$.

$\mathrm{Al}$ año siguiente falleció el maestro. Durán afirma que murió en 1589, y el trabajo lo continuó su hijo Juan quien recibió sucesivos pagos a cuenta hasta 1594 en que recibió la última entrega. Juan de Berroeta hizo también la caja del órgano, que fue sustituida a finales del siglo XVIII, y actualmente está en el cercano pueblo de Almudevar.

Hay una cierta confusión con los nombres de los maestros. Parece que este Juan Berroeta era yerno y que, de acuerdo con una expresión coloquial, en alguna ocasión se le identifica como hijo. Hay textos, no obstante, en que a éste se le denomina Juan Beraztegui. Por otra parte de la nota descubierta en el desmontaje del coro se comprueba que al maestro firmante, Nicolás de Berraztegui, también es denominado como Nicolás de Berroeta .

El encargo fue de 40 sillas altas y 30 bajas, pero tal como aparece en la capitulación se había incluido una cláusula que permitía la modificación de este número:

«Item, es pacto y condición que si según la proporcion y espacio del choro pudieren entrar mas de las quarenta sillas altas y trenta baxas y paresciere al cabildo que se hagan más, haya de hazer dicho mre. Nicholas todas las mas que el cabildo dixere, perfectas y de la mesma madera, obra e perficion que las otras, por el mesmo precio de cada silla alta y baxa que arriba se dice» ${ }^{6}$.

En realidad en la misma capitulación al sumar la cantidad a pagar, además de estas setenta sillas se añaden las cuatro de las esquinas y las tres de cabecera que ya estaban hechas. Todas ellas suman 77, más las dos puertas

En algún momento, no obstante, el Cabildo se acogió a esta cláusula y probablemente de acuerdo con las disponibilidades del espacio amplió el número hasta las 85 que había cuando el desmantelamiento, número que ya había contabilizado Aynsa. A ello hay que añadir dos puertas y un facistol. Todo de buen trabajo en madera de roble ${ }^{7}$.

Tanto Arco Garay como Durán Gudiol afirman que previamente fueron instaladas en la Sala Capitular, quizá deduciéndolo del punto primero de la capitulación, donde no queda claro. Arco afirma que el «capítulo viejo» o «sala de capítulos generales» era la sala existente en la parte del claustro que hoy llamamos románico ${ }^{8}$. La cita en cuestión dice: «... que son y están, las que el dicho mre. nicholas a armado y puesto en el caplo. viejo de la dicha iglesia»

Siempre se ha afirmado que la instalación de la Sala Capitular en el interior de la catedral, en la «capilla de Juan Martín de los Campaneros» fue en 1645. Lo cierto es que Aynsa habla, ya a principios del siglo xviI, de la existencia de un «capítulo» en el interior de la catedral. De todas formas quizá la lectura exacta en relación con las sillas hechas, no sea que estaban colocadas allí, sino que las que allí había eran una referencia para el trabajo que quedaba por hacer, pues la del obispo y asistentes, tal como se afirma en la capitulación estaban en el coro.

\footnotetext{
5 Arco Garay, R. del,«El Coro de la Catedral de Huesca» en Universidad, Revista de Cultura y Vida Universitaria, Zaragoza (octubre-diciembre 1949) p. 115.

6 Arco Garay, R. del, Ibidem, p. 117.

7 Aynsa Francisco, Diego, Fundación, excelencias, grandezas y cosas memorables de la antiquisima ciudad e Huesca, Huesca 1619 , p. 510.

${ }^{8}$ Arco Garay, R. del, «El Arte en la Catedral de Huesca, noticias arqueológicas y documentales inéditas», en Vell y nou, vol. I, núm. X, época II, enero 1921, p. 388.
}

AEA, LXXVI, 2003, 302, pp. 153 a 167 


\section{Iconografía}

El conjunto fue hecho con una gran profusión de figuras de las que se contabilizan más de 1500, cómputo en el que se incluyen las caras, las figuras de medio cuerpo, y todas las figuras desde las más pequeñas, de unos centímetros, hasta las de los paneles de los sédalos de los canónigos que tienen la altura de unos 90 centímetros. No queda claro si este conjunto responde a una idea previa o programa preestablecido, y menos claro quedará en el futuro precisamente por haber sido levantada la sillería sin la precaución previa de recoger información sobre la situación exacta de cada uno de las piezas. Lo cierto es que tal como se deduce de la capitulación, el cabildo era consciente de la relevancia de este aspecto pues los capitulares se habían reservado en el protocolo «... la orden en las figuras y lo demás que el cabildo le dixere» 9 . Afortunadamente Tormo Cervino, hijo de Don Elías Tormo, publicó un recuento en 1942, que aunque con equivocaciones en alguna identificación, las menos, es una inestimable referencia y ha resultado un buen soporte en los trabajos de recomposición. Después, Don Ricardo del Arco, y Don Antonio Durán, y otros autores, se han servido de él haciendo algunas precisiones ${ }^{10}$.

Particularmente curioso resulta la presencia de temas mitológicos entre los motivos ornamentales de la sillería. De forma un tanto enigmática entre las figurillas portantes de los posabrazos aparece un fraile, la única persona totalmente vestida, que en vez de brazos tiene espirales. No faltan entre todas estos soportes seres híbridos de concepción fantástica, propia de la ornamentación de la época, y, consecuentemente, monstruosos, y, algunas, con posturas ambiguas que por ello pueden dar lugar a interpretaciones malintecionadas, quizá relacionadas con algún vicio, que previsiblemente pretenderían recordar como censurable.

Pero lo más desconcertante es ver la gran cantidad de figuras y figuritas, presentadas en desnudo integral. De todas formas hay que observar que no hay desnudos femeninos completos. Hay que precisar al respecto que la sillería se hace a finales del siglo XVI, dos décadas después de terminar el Concilio de Trento que había regulado el uso de las imágenes en la iglesias proscribiendo el desnudo, y por supuesto, temas profanos y determinados desnudos, considerados como lascivos. Con ello, y para evitar equívocos que no pretendo suscitar, no estoy dando a entender que la sillería tenga una especial carga de temas eróticos.

Al igual que se ha constatado en otras sillerías, la razón de la presencia de figuras de ascendencia mitológica puede estar en el contenido moralizante del que se les hacía portadoras, a no ser que la posibilidad de esta lectura fuera el pretexto para justificar la galería de figuras comentadas. En este conjunto no falta la figura de Hércules, preanunciadora en otras sillerías de la figura de Cristo. En todo caso, habrá que tener presente que los resultados finales son posteriores al concilio ${ }^{11}$.

Se constata, no obstante, que esta iconografía, está en las sillas propiamente dichas, quizá

\footnotetext{
9 Arco Garay, R. del,«El Coro de la Catedral de Huesca» en Universidad, Revista de Cultura y Vida Universitaria, Zaragoza (octubre-diciembre 1949), p. 114.

10 Arco Garay, R. del, «El Coro de la Catedral de Huesca» en Universidad, Revista de Cultura y Vida Universitaria Zaragoza (octubre-diciembre 1949) p. 114; Arco Garay, R. del, «La Sillería del Coro de la Catedral de Huesca», Zaragoza, Cuadernos de Arte Aragonés, núm. 5, 1953, p. 8.; Durán Gudiol, A., Historia de la Catedral de Huesca Huesca, IEA 1991, pp. 183 y 185: introduce variaciones; Cardesa, T., «La diversidad de estilos en la sillería coral de la catedral oscense», en Don Antonio Durán Gudiol, Homenaje, Huesca, 1995, pp. 115-161; Cardesa, T.: Sitiales de la sillería coral de la catedral de Huesca, en Signos I, Huesca 1994, p. 216. Esta en trámite de publicación una tesis sobre Las sillerías del Alto Aragón en el siglo XVI, realizada por la doctora Isabel Romanos.

"Se han publicado algunos estudios relacionados con la iconografía de las sillerías. Preferentemente están referidos a época gótica. Entre ellos hay que aludir a los de la investigadora de CSIC Isabel Mateo. El más próximo a la de Huesca, por aparecer también en ella la figura del héroe mitológico, sería «Los trabajos de Hércules en las sillerías de coro españolas» en AEA núm. 189, pp. 43- 55 (1976), J. Fco. Esteban Llorente, «Los dioses paganos en las iglesias españolas del siglo xvi, en Boletín del Museo e Instituto Camon Aznar, núm. 88 (2000), pp. 157-191.
} 
marcando dos niveles que corresponderían a los asientos propiamente dichos de los clérigos y el de los respaldos y doseles de los asientos altos. Hecha excepción en esta apreciación de las figurillas que aparecen en frisos, meramente ornamentales, y las de los canetes, que no parece que tengan otra función. Puede estar en relación con una pretendida erudición de los ocupantes en relación con metas superiores a las que debían tender o referencias que debían tener presentes.

La sillería, en definitiva, es un conjunto escultórico destacado, que reproduce una mezcla de figuras de ascendencia cristiana con otras que constituían el bagaje cultural de la época. Probablemente los maestros se limitaron a tener delante distintas fuentes gráficas donde se inspiraron, sin que parezca, como queda dicho, que hubiera una exigencia muy rigorista por parte de los capitulares.

Finalmente, como elemento anecdótico, curioso y enigmático, está la figura de un perro sentado sobre sus cuartos traseros, que parece gemir, razón por la que lleva un pañuelo en la mano. Ocupa el lugar de una de estas caras, el correspondiente a la silla de beneficiados del lado de la epístola, cuyo lateral servía de pasillo a la puerta. Está situada en el museo en el emplazamiento que tuvo originalmente.

Esta sillería no se identifica con el abigarramiento decorativo de las más sobresalientes y bellas sillerías de coros españoles, sino que, dado el momento en que fue hecha, se caracteriza por una más permeable distribución de los elementos en una composición más sobria de concepción clasicista, aunque no al margen de recuerdos platerescos de décadas anteriores. En el conjunto hay figuras de exquisito tallado que evidencian el conocimiento exacto de la anatomía por parte del maestro y un sentido de idealización de la figura humana acorde con el gusto identificado con el renacimiento. Entre estos particularmente destacados son los atlantes de los canetes, tallados en bulto redondo. Por supuesto el santoral de los paneles constituye un interesante muestrario escultórico en el que sobresalen algunos santos, tallados con precisión de maestro y soltura de artista que conocía los cánones clásicos y usó con moderación las soluciones de ascendencia manierista.

Del conjunto formaba parte un monumental facistol bello y proporcionado, que tenía tallado el cimborrio de remate y las ocho portezuelas que cerraban los armarios de la parte baja. Está documentado a finales del siglo XVIII, pero probablemente las portezuelas eran de otro anterior del siglo $\mathrm{XVI}{ }^{12}$.

\section{Fragmentación de la sillería}

Tal como queda recogido, se desmontó sin saber exactamente que se iba a hacer con ella. Yo mismo manifesté mi sorpresa y preocupación cuando se habló de ello. Es una compensación la satisfacción de haber tenido la oportunidad de disponer la forma de recuperar los restos 30 años después,

En la década de los cincuenta uno de los canónigos había escrito una colaboración en la revista local Argensola que titulaba Coros antitéticos y antilitúrgicos (A propósito de las obras de reconstrucción de la Catedral de Huesca). Con posterioridad, siendo deán este autor, fue desmontado el coro y una parte, exactamente un total de 28 sitiales, 16 de ellos de canónigos, fueron instalados a ambos lados de la capilla mayor. El frente de este presbiterio, no admitía ninguna silla, pues el retablo mayor es la gran obra esculpida en alabastro por Damián For-

12 Arco Garay, R. del, «El Arte en la Catedral de Huesca, noticias arqueológicas y documentales inéditas», en Vell y nou, vol. I, núm. X, época II, enero 1921, p. 392.

AEA, LXXVI, 2003, 302, pp. 153 a 167 
ment. Para hacer este acomodo era imprescindible separar algunas sillas desgajando, consecuentemente, laterales que estaban relacionados y por los que resbalaba la misericordia ${ }^{13}$.

Las sillas de los canónigos tienen numeradas por la parte de atrás, desde la época del tallado, una parte de las piezas, lo que facilitaba saber qué paneles con los bajorrelieves de los santos correspondían en cada sitial. No se mantuvieron los paneles originales en algunas de las sillas seleccionadas y recolocadas en el presbiterio. Hubo, en consecuencia, una mezcla de sillas y paneles de forma que algunas de ellas que tenían paneles de santas fueron despojados de esta iconografía para acomodar en su sustitución una parte de los paneles que originalmente habían estado en la cabecera del coro y que correspondían básicamente al apostolado. Con fundamento o quizá simplemente por chanza, se ha dicho que el clero, que levantaba la sillería, por acomodarse a las sugerencias del Concilio Vaticano II, no quería mujeres en el presbiterio, ni en apariencia.

El arquitecto Pons Sorolla, que es quien redactó el proyecto de restauración hizo una propuesta que consistía en mantener en los intercolumnios que separan las naves los tramos laterales de la sillería, de forma semejante a como están, por ejemplo, en la catedral de Tarragona, desplazando al presbiterio el sector principal del coro, el que cortaba la nave en su emplazamiento original. Lamentablemente esta propuesta, no se sabe exactamente por qué no se llevó a término. Hubiera sido menos mala, una vez tomada la opción de abrir el coro.

Unos años después, el arquitecto que le sustituyó, con ocasión de intervenciones en el entorno de la Catedral, viendo que estaba el resto de la sillería abandonado, hizo lo que a su alcance estaba para adaptarla en la sala capitular. Dadas las dimensiones de este espacio, no cabían todas las piezas. Al no disponer de documentación gráfica, entonces se mezclaron algunas piezas, y quizá por contar con pocos recursos, el montaje se hizo con poco cuidado, empleándose gran cantidad de clavos que de momento sujetaban el mueble pero que contribuyeron a su deterioro.

\section{Recuperación de los restos de la sillería}

En el momento en que nos hicimos cargo de las piezas se constató que habían desaparecido el facistol y las puertas laterales de acceso al coro. No se ha podido obtener información para seguir la posible pista.

Fue entonces cuando buscada documentación de apoyo, principalmente gráfica, se comprobó que no existe ni en Huesca ni en Madrid. La existente en el archivo MAS, correspondía al lateral izquierdo o lado del evangelio, más apta para fotografía de exposición prolongada como consecuencia de la incidencia de la luz natural, proveniente del mediodía.

La parte de la sillería llevada a la sala capitular fue montada sin rigor intercambiándose algunos respaldos, cosa en parte inevitable al haber seleccionado algunos de ellos para las sillas colocadas en el presbiterio de la catedral.

Desmontada la sillería por haber sido destinada la sala capitular a Sala de Orfebrería del Museo Diocesano, se buscó otro emplazamiento donde lo que había sobrevivido fuera recompuesto de forma que manifestara, al menos, parte del esplendor que hasta su desmontaje había caracterizado al conjunto. No existía en todo el entorno de la catedral un espacio de ancho suficiente o equivalente al de la nave central de la catedral, donde se pudiera volver a instalar la sillería recomponiéndola en su integridad. Tampoco resultaba viable la colocación en los

\footnotetext{
13 Clemente Lalueza, J., «Coros antitéticos y antilitúrgicos (A propósito de las obras de reconstrucción de la Catedral de Huesca)» en Argensola, núm. 23, 1955, pp. 271-275.
} 
laterales de la nave central, de acuerdo con una de las propuestas formuladas en el momento de su desmontaje. Probablemente era la mejor solución, pero suponía lógicamente volver a desmontar la del presbiterio. La falta de colaboración por parte del cabildo que se oponía a que fuera removida de la sala capitular, desaconsejaba el intento de esta solución.

El espacio que mejor posibilidades ofrecía para acomodar lo que de la sillería quedaba era el coro alto de la parroquia de la catedral, que en Huesca y Zaragoza, se identifica como «parroquieta». La de Huesca es edificio bastante grande y de buena construcción que el pasado siglo, entre 1884 y 1888, fue construido en el centro del nunca acabado claustro gótico. El coro alto de esta iglesia, de todas formas, era insuficiente, por lo que fue necesario prolongarlo en un tramo. Por razones de economía se había pensado que cada uno de los dos tramos de tres sillas podían ser colocadas en los laterales del altar del castillo-abadía de Monteragón que preside la misma sala, antigua iglesia, pero en la medida en que avanzó el montaje, se comprobó que eran las más incompletas y mutiladas. Esta constatación sugirió una nueva ampliación del coro mediante galerías laterales o cantorías, que lo prolongaran por los laterales. Adoptada esta nueva ampliación se obtuvo un espacio que permitía compaginar la estructura soporte de la sillería con la nueva sala de museo. No fue posible planificar esta solución desde el principio, porque, a falta de la mencionada documentación, hubo que solucionar los problemas en la medida en que se iba montando.

En la catedral básicamente habían sido colocadas sillas del lateral del evangelio, además de las centrales del fondo. La parte, por lo tanto, a recolocar, tanto sillas altas como bajas, era la del lado opuesto, todo el lateral derecho mirando al altar mayor, es decir del lado de la epístola. El nuevo espacio disponible no era tan largo como para acomodar todo un lateral de 19 sillas en línea, más la puerta, que era la longitud original. Comenzando desde el rincón, fueron colocadas las sillas que siempre estuvieron en el frente (números originales 31-32-33) y los del lateral de la epístola, números del 34 al 46, la puerta, número 47, y los tres últimas sillas (5354-55) que de esta forma mantenían su posición original de extremo en el conjunto. Quedaban las cinco (números 48 al 52) que estuvieron entre este extremo y la puerta numerada con el 47 , Estas cinco fueron colocadas en el frente del actual emplazamiento, a continuación de las primeras enumeradas. Con respecto a las sillas bajas, sin numeración original, todo el ángulo formado por un total de once sillas ha sido colocado en el puesto que les correspondía. Las siete de beneficiados que estuvieron colocadas a continuación del pasillo lateral de acceso desde la nave de la epístola, en dirección al presbiterio, han sido colocadas frente a las anteriores.

Tras éstas, por lo tanto en el lado del evangelio, en el nivel correspondiente a las sillas de los canónigos, fueron colocadas las sillas del 1 al 8 , que originalmente eran el otro extremo del coro, a partir de la reja de cerramiento del conjunto. Junto a la número 8 , en el lugar que le correspondía, coincidiendo con el actual acceso, fue colocado lo que quedaba del tramo correspondiente a la otra puerta lateral, numerada con el 9. En el extremo opuesto de este lado, en el lugar de la cantoría, fueron colocadas los números 19,18 y 17, separadas de la número 1, para que de ésta se viera el ángulo o vuelta en que remataba la sillería y conectaba con la reja.

Por lo tanto, sólo para una parte de las sillas se podía mantener su situación original. El conjunto configura algo así como un coro, pero sin dar el equívoco de que ese fue el aspecto original del coro.

La sillería original fue compuesta por 85 sillas. De ellas fueron colocadas en el presbiterio de la catedral 28. En el nuevo emplazamiento del museo hay 56. Junto a la actual barandilla, en la alineación de beneficiados del lado de la epístola, hay una suelta, allí colocada para entender mejor como funcionaba el acceso por las puertas laterales. Para poder montarla hubo que reponer varias piezas. Ha quedado, por lo tanto, solamente una por recuperar. Era la otra de las sillas esquineras de beneficiados. De ella quedan disponibles solamente las piezas cen- 
trales, al haber sido reutilizadas en la catedral los laterales. El friso de esta silla, más largo que los de las otras, por la razón de su ubicación en esquina, ha sido colocado sobre la puerta recompuesta, allí donde hubo otro, desaparecido con la puerta. Los restos de esta silla corresponden a la silla del ángulo de beneficiados del lado del evangelio, cuyos laterales se hallan separados en cada uno de los lados del presbiterio de la catedral. Son, por lo tanto, 84 sillas las que se pueden contemplar en dos ubicaciones diferenciadas.

Las sillas no fueron talladas con un mismo ancho rigurosamente mantenido lo que ocasiona por ejemplo que las de los canónigos del lado del evangelio, actual emplazamiento, no correspondan en alineación a la de los beneficiados, y ambas estén desalineadas con las que son frontales. Por el criterio claro de conservar las sillas íntegras, acomodándolas al espacio disponible, el acceso central a las sillas altas del fondo, actualmente es tan estrecho que resulta lógicamente inverosímil, y más para la volumetría que solía caracterizar la silueta de algunos canónigos. Sin embargo, se ha mantenido el mismo desnivel y distancia entre la alineación de la de canónigos y beneficiados, de acuerdo con la modulación que le dieron los maestros carpinteros y talladores.

Perdido el original y bello facistol, se ha colocado en el centro uno disponible, más pequeño y sencillo, de nogal con sencillísimas incrustaciones en taracea, que sirve para dar idea del funcionamiento de estos espacios. Estaba en el coro de la «parroquieta», pero no se sabe si fue hecho para este lugar, siendo probable que proceda de alguno de los conventos desamortizados en la ciudad.

\section{Criterios de montaje}

En el momento de planificar la recuperación de las piezas no expuestas en el presbiterio de la catedral para su exposición en la nueva sala, se adoptaron una serie de pautas que han regido la operación de recolocación.

- Desde el primer momento ha sido criterio rector el salvar el máximo posible de piezas, respetar la forma original de montaje, intentar, al menos, no eliminar o mutilar ningún apéndice por superficial que resultara y descontextualizado que hubiera quedado

- Siempre que las piezas ofrecían información con respecto a su ensamblaje original, este se ha mantenido. Cuando faltaban piezas porque habían sido seleccionadas para el presbiterio, o entre las conservadas no era posible identificarlas por carecer de numeración, de entre ellas se iban seleccionado aquellas que mejor encajaban sin tener que modificarlas.

- Era incuestionable que no se podían fragmentar más los tramos, y que por lo tanto, había que acomodarlos al nuevo espacio. Aquellas secuencias de sédalos que se podían recomponer de acuerdo con su numeración, se han mantenido unidos, asumiendo la consecuencia de tener que desplazarlas a otro punto del conjunto, para acomodarlas al espacio disponible.

- Se ha optado por la reintegración de las piezas que faltaban. Éstas si no llevan la fecha de colocación u otro signo, son diferenciables por las texturas de los cortes. A excepción de los acanaladuras de las columnas, y caulículos y follaje de capiteles, se ha eludido imitar la decoración en las piezas nuevas, marcando únicamente la geometrización que compartimentaba esta decoración. En los dos copetes rehechos las figuras enmarcantes están insinuadas en su volumetría, no en los detalles. En la puerta recompuesta, se ha mantenido la estructura y dimensiones y se ha repuesto únicamente la geometrización desechando imitar los molduración en bajorrelieve

- Fue formulada la propuesta de no usar tornillería, pero, lo cierto es, que, a veces, ha sido imprescindible, 


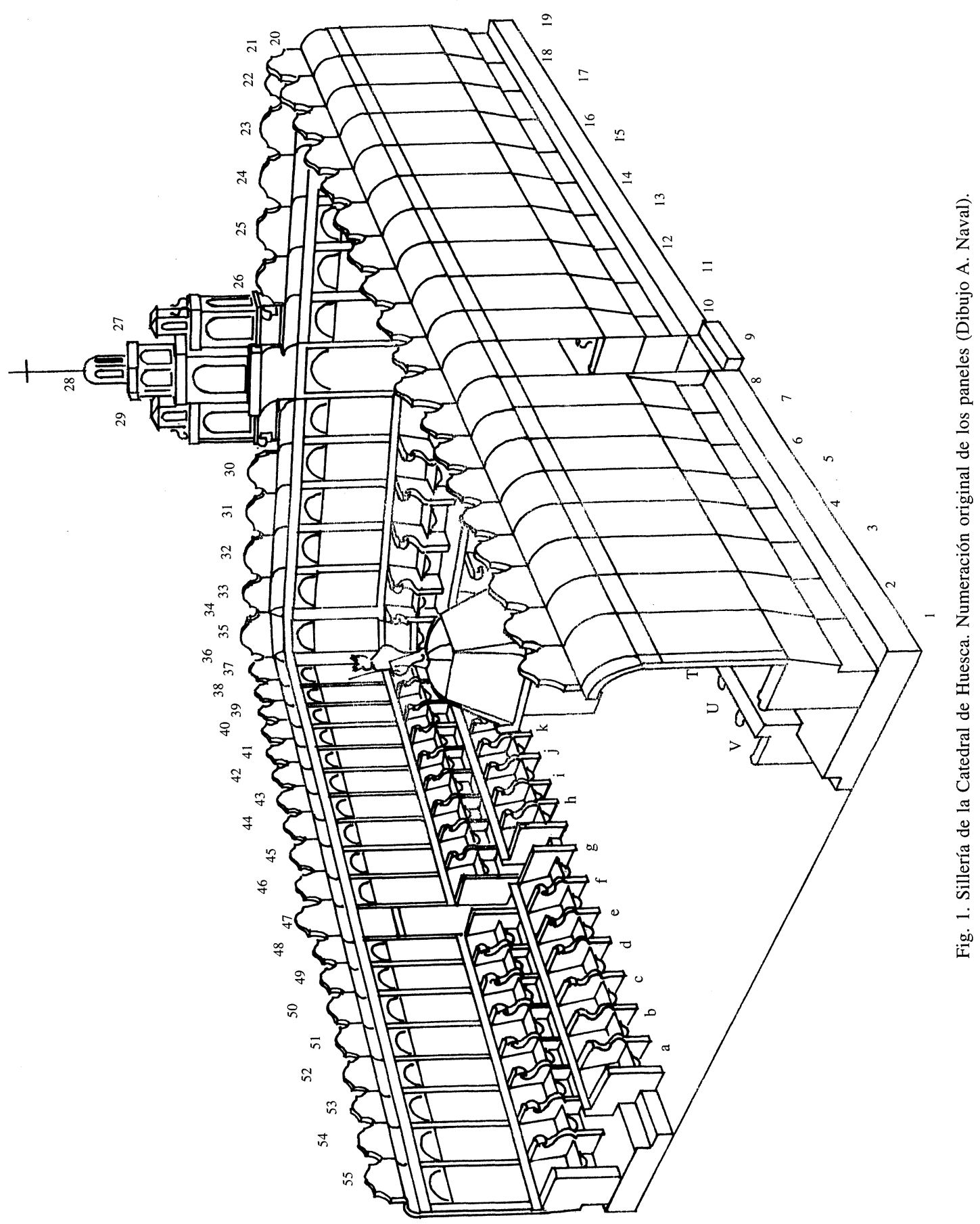


Notas del material y sus repercusiones en el montaje

Constituyó un importante punto de apoyo que las piezas de las sillas de canónigos fueran numeradas en el siglo xvI, pero como queda dicho, hay fallos y equivocaciones. Las piezas pequeñas que numéricamente son más, no tienen numeración. Las sillas altas tienen numeradas casi todas las piezas que componían cada módulo con el mismo número correlativo en cada una de ellas, pero algunas carecen de ella. Hay, sin embargo, algunos olvidos, y una equivocación en los hastiales o copetes de remate, motivado por los paneles número 34 y 36, que no corresponden a sillas, y que por su estrechez tampoco podían alojar un copete. Son los que en la actualidad son colaterales al panel de Santa Lucía, en el ángulo de canónigos. El que numeró estas piezas no se percató de ello adjudicando a estos tramos un copete numerado que luego no pudieron colocar.

Entre las piezas sobrantes había numerosas molduras que, rectificadas cuando se hizo el montaje de la catedral, posteriormente fueron desechadas multiplicándose los fragmentos e incrementando las lagunas, lo que obligó a hacer algunos tramos de molduras nuevas. Algunas molduras, en las recolocaciones previas del presbiterio y sala capitular, fueron seleccionadas sin una aparente razón justificada, y acomodadas sin sopesar con exactitud su destino, para lo cual se hicieron numerosos cortes que generaron fragmentos. Esto motivó el tener que hacer molduras nuevas. La cosa fue más complicada cuando se trataba de salientes en las molduras.

Asimismo, al fragmentar los tramos de sillería, o agrupaciones de sillas, se multiplicaron los bordes que originalmente estaban encajados de dos en dos en cada columna o pie derecho, lo que obligó a hacer otros nuevos. Esto ha sido necesario también para los atlantes acomodados en los canetes. Estos han sido repuestos sin talla, lo que permite diferenciarlos fácilmente. Por la misma razón de multiplicación de bordes, fueron llevados a la catedral los laterales de pasillo lo que ha obligado a hacer cinco nuevos que mantienen dimensiones, pero quedan desprovistos de la ornamentación en bajorrelieve.

Cada módulo, sédalo, fue cortado y montado de acuerdo con un mismo patrón y medida, en torno a los 70 centímetros, pero este corte no se hizo con rigor milimétrico. Cada pieza, sin embargo, encajaba perfectamente en el lugar para el que fue hecho, de forma que, al cambiar la colocación de los primeros paneles, ha supuesto una alteración en cadena, obligando, muchas veces inevitablemente, a acomodar mediante cepillado o corte de algunos milímetros.

La sillería estuvo perfectamente alineada y aplomada en su emplazamiento original, tal como todavía se puede comprobar por algunas fotografías antiguas. Ahora, en la recolocación, no siempre ha sido posible recuperar el equilibrio de montaje que le caracterizó, por las deformaciones adquiridas. Algunas piezas estaban deformadas, por el tiempo que estuvieron descolocadas, mal recolocadas, o mal depositadas, lo que obligó a acomodarlas mediante tornillería, después de forzarlas mediante gatos de carpintero. La madera es extraordinariamente sensible a las alteraciones medioambientales necesitando de un largo periodo de adaptación hasta estabilizar las oscilaciones.

Parte de la estabilidad que le caracterizaba en su emplazamiento original se debía a que estaba perfectamente arriostrada. En la nueva ubicación, al no tener el soporte que le proporcionaba la reja que cerraba el coro, ha habido que estabilizar las últimas sillas, reforzándola por la parte posterior.

En la obra original, sólo en contados casos usaron clavos, aunque cuando los hicieron llegaron a ser enormes. Lo mismo hay que decir de la cola que fue de la que, hasta tiempos muy recientes, era de calentar. La espiga de madera fue el anclaje preferente. No ha sido posible mantener este criterio de montaje por las deformaciones antes señaladas. 
La madera empleada fue el roble, nogal y pino para puertas y obras de mazonería. Los troncos o piezas usadas en las nacelas, o «tejas» de los profetas, fueron enormes dadas las dimensiones obtenidas. Esta pieza es curvada, a manera de caveto o nacela, pero no como consecuencia de haber forzado la madera hasta obtener la curvatura, sino como fruto de haber sido tallada la figura y panel de soporte en gruesos troncos. La curvatura se consiguió por eliminación de material, no por acomodación. Es lo que los carpinteros identificaron como teja, por parecer el fragmento de una muy grande.

La madera utilizada es de apreciable calidad. Tuvo que estar mucho tiempo en secado y acomodación, tal como era usual para los trabajos relevantes, y costumbre entre los buenos carpinteros. Las distintas coloraciones son debidas a los distintos árboles empleados. La conservación del conjunto es buena, y sólo en reducidas zonas acusaba huellas de xilófagos. Afortunadamente la lesión por humedad es escasa y puntual. El mayor deterioro venía dado por causas antrópicas, y se acusaba en la parte baja o nivel de uso ordinario.

La madera incorporada ha sido de roble cuando se trataba de piezas de reposición, y tablero DM hidrófugo, ignífugo y antixilófagos en la estructura de soporte y anclajes a los muros. Estos tirantes por la parte del muro apoyan sobre tacos de pino tratados con antixilófagos. La estructura portante de las sillas altas también es de tablero DM. La tarima necesariamente tenía que ser de pino. El barniz usado en la tarima es ignífugo.

Toda la sillería ha sido lavada con una mezcla especial de jabón suave y aguarrás, y se le dio una primera capa de cera virgen disuelta en aguarrás. Esta limpieza tuvo que hacerse con especial insistencia en las zonas bajas o de asiento, particularmente la de beneficiados donde era más que suciedad lo que había. Este lavado descompensó un tanto la tonalidad del conjunto. El terminado final fue mediante la misma disolución recuperando la calidad natural del roble. Por exigencia de la descompensación mencionada hubo que dar una suave coloración al último toque de cera. En realidad la sillería ya había recibido una coloración unificadora en algún momento, que fue eliminado con la limpieza. De todas formas el objetivo fue mantener la coloración natural del roble, que se acerca a la del tabaco. Los tableros traseros de las sillas de beneficiados, son de pino, y tenían barnices descompuestos y craquelados que fueron eliminados, al igual que las distintas capas de cera con que fue recubierta la madera. Por el contrario, las piezas conservadas en el presbiterio no fueron desprovistas de los sucesivos barnizados y gérmenes adheridos a lo largo del tiempo, lo que quizá aliente, al mismo tiempo que permitirá en el futuro, si eso se cree conveniente, los más variados análisis de laboratorio. Las partes de asiento propiamente dicho por su uso diario durante cuatrocientos años estaban especialmente mugrientas lo que forzó a una limpieza más intensa. De ellas todavía estaban peor las sillas bajas o de beneficiados pues siempre fueron las más accesibles. A su vez, éstas son las que más deteriorados tienen los trabajos esculpidos. En los últimos tiempos de vida de la sillería en el centro de la catedral, era frecuente ver sentados en ellas los «infanticos» de la catedral, frecuentemente aburridos durante las largas ceremonias, y, muchas veces, no ajenos a un trabajo de modificación de las anatomías de los distintas figurillas.

La iluminación incorporada ha sido de fibra óptica, cuyos generadores fueron colocados en las cámaras que quedan entre las sillas y los muros, y los mazos van por el interior de la estructura bajo la tarima, donde hubo que abrir conductos que no estaban previstos. En la tarima hay tablas que han quedado desprovistos del machiembrado para poder acceder a los mazos de fibra simplemente levantándolos.

La iluminación que proporciona esta técnica ofrece resultados altamente satisfactorios pues envuelven al conjunto en una veladura blanca continuada que la impregna de misterio. 


\section{Alteraciones destacables, consecuencia de la nueva ubicación}

En la relación que sigue se mantiene la numeración original que es la que incluyeron con pintura negra los carpinteros del siglo XvI.

En la silla número 31 fue colocado el panel número 11, que lleva la imagen de Santa Catalina (le hubiera correspondido Santiago); en la silla 32, el panel número 15, con San Valero (le hubiera correspondido San Simón); en la 33, el 16, con San Agustín (le hubiera correspondido San Tadeo).

En la silla esquinera numero 35 fue colocado el panel número 10, con Santa Lucía (le hubiera correspondido San Bartolomé). En la número 37 el número 14, con San Roque (le hubiera correspondido San Matías). En la 38, el 13, con San Orencio, padre (le hubiera correspondido San Juan Bautista). Todos ellos, sustituyeron inevitablemente los paneles llevados al presbiterio de la catedral, de cuyas sillas fueron sacados.

El resto de sillas de esta alineación conserva los paneles que les adjudicaron en el siglo Xvi, así como en las sillas números 52, 51 y 50 .

Sin embargo en las sillas números 49 y 48 , situadas en el extremo del fondo, fueron permutados. Encajaban mejor invertidos.

En el lateral del evangelio, izquierda mi-

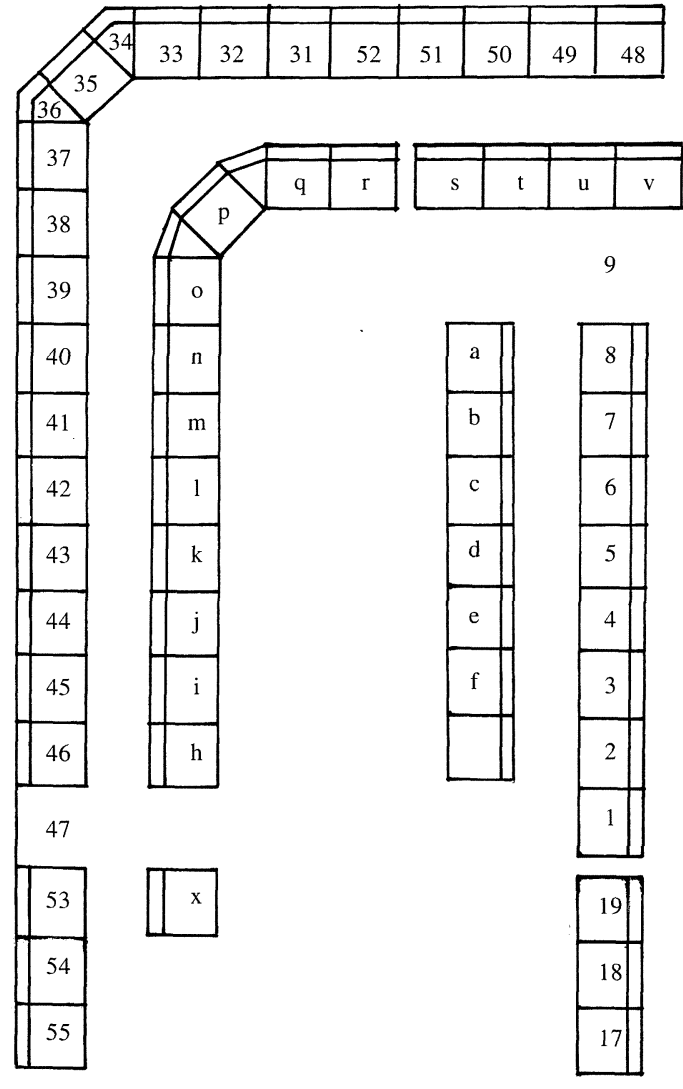

Fig. 2. Sillería de la Catedral de Huesca. Ubicación actual de las sillas. rando al frente, las sillas números del 8 al 1, conservan los paneles que les correspondían.

En el 19, le hubiera correspondido San Miguel, (llevado a la catedral) pero hubo que colocar el 18, para, en el 18, poder acomodar el de Santa Paciencia, que estaba sobrante y que no tenía número. Era la forma de modificar menos las piezas para su ensamblaje. Se intentó colocar este panel junto al de San Orencio, su esposo, pero no encajaba. La silla número 17 conserva el panel que le correspondía.

Respecto a los copetes o hastiales de remate, los que estaban desplazados fueron distribuidos para llenar los vacíos ocasionados por los llevados a la catedral, con el resultado siguiente: en la silla número 55, está el número 36; en la 54, está el 29; en la 53, el 22. El de la puerta está en su lugar. Después, hasta la silla número 31 conservan los que les correspondían. Uno, sin número, fue colocado en la silla número 52, y en la número 51 está el copete número 12. Los números 50, 49 y 48 están en sus emplazamientos correspondientes.

En el lateral del evangelio conservan los hastiales originales las sillas de los números 8 al 2 , pero en la silla número 1 , fue colocado uno de los desplazados que tiene el número 10 . No hubo copete para las dos sillas contiguas la 19 y 18 por haber sido colocados en la catedral dos que desempeñan la función de remate de los laterales que hacen frente a la nave. Han sido reintegrados quedando diferenciados, tal como queda dicho mediante figuras enmarcantes simplemente insinuadas, además de estar señalados por la parte de atrás En la silla número 17 está 

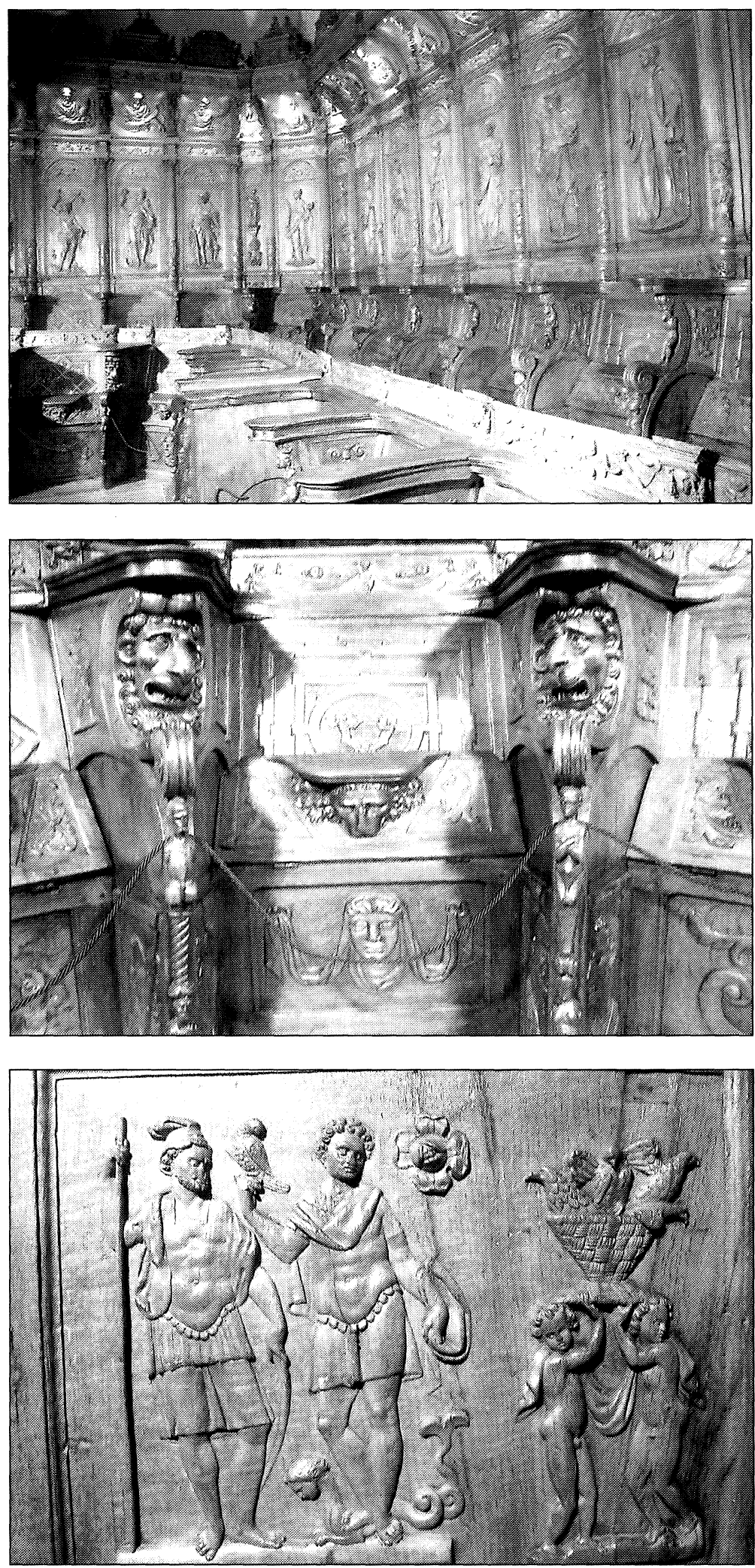

Figs. 3, 4, 5. Sillería de la Catedral de Huesca. Museo Diocesano. Vista parcial y detalles.

AEA, LXXVI, 2003, 302, pp. 153 a 167 
el que le correspondía originalmente. Probablemente la selección hecha para la catedral fue en función de que tuvieran el perfil de una cara en el medallón del centro.

Especiales problemas causaron la reposición de las cornisas portantes de los hastiales, teniendo que hacer remiendos en las de las sillas números 54 y 53, 32 y 31, 8 y 7, y en la 19.

En la silla número 46 el profeta de la nacela es de procedencia desconocida al no tener número. Para encajarlo, hubo que recortarlo en 5 centímetros, sin tocar la imagen. También hubo que adaptar en la silla 31 el profeta número 24 . El friso sobre el que apoya esta pieza es de adaptación con piezas numeradas con el 24, así como en el friso contiguo del 31.

Piezas de menor volumetría, como eran los tambores de zócalos de las columnas o molduras situadas sobre los capiteles, al no estar numeradas, pueden haber cambiado su emplazamiento original.

Al final del montaje de las 56 sillas se habían ensamblado más de 2.000 piezas, de todas las dimensiones. La verdad es que al margen de la lamentable desaparición de las dos puertas, y la fragmentación de molduras con la consiguiente pérdida de fragmentos, solo se ha constatado la desaparición de una pieza tallada, la del friso de la silla número 53. Se han colocado todas las conservadas, a excepción, como queda dicho, de los restos de la silla esquinera de beneficiados

El relato que precede esta motivado tanto por el deseo de dejar constancia a aquellos que pretendan, quizá con otras posibilidades, recomponer el conjunto, como de llamada de atención ante otros intentos de desmontaje de sillerías españolas. La de Huesca se desmontó en un mal momento, tomando decisiones no suficientemente sopesadas. Coincidió también con el cambio de obispo en la Diócesis. Si lo que se perseguía era mayor amplitud en la catedral ésta amplitud se hubiera conseguido suficientemente retrasando un tramo todo el coro. El templo no hubiera tenido menos capacidad de la que tiene ahora. De todas formas, dada la importancia de la obra de carpintería, aún esto hubiera sido discutible, pues en el traslado indudablemente iba a sufrir el mueble. Ciertamente que ha sufrido en los años que ha carecido de una atención adecuada, quedando abandonada a su propia suerte.

La sillería sufrió con el desmontaje heridas serias y mutilaciones que han sido irreparables, pero después de 32 años, ha sido salvada prácticamente en su integridad, de forma que si generaciones venideras quieren recomponerla volviendo a unificarla en un espacio que hoy no existe en el entorno de la catedral, podrán hacerlo. Quede como sugerencia, de todas formas, por si se da esa oportunidad, deberán sopesar meticulosamente la oportunidad de un nuevo desmonaje para su posterior acomodación. Una nueva manipulación incrementaría considerablemente el deterioro ${ }^{14}$.

La Diputación General de Aragón, se hizo cargo de la ampliación de las cantorías laterales y de la iluminación con fibra óptica. La prolongación del coro y toda la operación de montaje, se ha hecho con cargo exclusivamente de la administración de la diócesis, como compromiso por el desmantelamiento que un día hizo el cabildo, pero constituyendo un notable esfuerzo, dados los recursos de toda administración diocesana reducida. Esto supuso asumir las limitaciones que no se hubieran dado con los presupuestos generalmente pródigos que piden los especialistas y empresas que se dicen especializadas, a los que suele dar acceso generosamente la administración por encima de lo razonable. En la operación del montaje de la sillería de Huesca hubo que racionalizar los recursos, y asumir las disponibilidades técnicas. En todo caso ha habido dedicación, esfuerzo y entusiasmo desinteresado. Quienes puedan verla valorarán los resultados. Cualquiera, de nuevo, puede contemplar el conjunto de sillas, aunque a partir de ahora por las circunstancias de los tiempos están en dos ubicaciones diferentes.

\footnotetext{
14 En el archivo diocesano queda depositada una memoria con incidencias más pormenorizadas.
} 